\section{Effects of Lime Sulfur and Fish Oil on Pollen Tube Growth, Leaf Photosynthesis and Fruit Set in Apple}

\author{
Steven McArtney ${ }^{1}$ \\ HortResearch, Hawke's Bay Research Centre, Private Bag 1401, Havelock \\ North, New Zealand
}

John Palmer, Sue Davies, and Shona Seymour
HortResearch, Nelson Research Centre, P.O. Box 220, Motueka, New Zealand

Additional index words. fruit abscission, bloom thinning, organic apple production, Malus

$\times$ domestica

\begin{abstract}
The effect of liquid lime sulfur (LS) and fish oil (FO) application during bloom on leaf photosynthesis (Pn) and pollen tube growth in apple (Malus $\times$ domestica) flowers were investigated in order to determine their mode of action as a bloom thinning agent. LS increased the percentage of flowers with fewer than $\mathbf{1 0}$ pollen tubes per flower to more than $64 \%$ compared to $5 \%$ or less in the control. Pollen tubes were completely absent from $\mathbf{2 7 \%}$ to $\mathbf{4 8 \%}$ of flowers following LS treatment compared with fewer than $4 \%$ of flowers having no pollen tubes on control trees. These data indicate that $30 \%$ to $50 \%$ of flowers that open on the day of LS application are unlikely to set a fruit due to the complete inhibition of embryo fertilization. Increasing the rate of LS from $0.5 \%$ to $4 \%$ increased the proportion of flowers with limited pollen tube number in a concentration dependent manner. LS suppressed the rate of light saturated Pn; successive LS sprays during the bloom period had an additive effect on suppression of Pn and fruit set. In one study the reduction in Pn was greatest 12 days after application of LS but Pn recovered by about 19 days after initial treatment. In a second study Pn of primary spur leaves had still not recovered when measured 57 days after the first of three applications. FO had no effect on the number of pollen tubes per flower, but reduced $P n$ and fruit set by about $10 \%$ and $20 \%$ respectively. An increase in the proportion of flowers with no pollen tubes, and therefore no embryo development, can account, at least in part, for the thinning response following application of LS to apples during bloom. It is likely that suppression of Pn contributes to the thinning response, although the importance of this mechanism will depend on perturbation of the total carbohydrate supply to developing fruit.
\end{abstract}

Liquid lime sulfur (LS, calcium polysulfate) is frequently used as a bloom-thinning agent in organic apple production systems in countries where its use is permitted, and is increasingly being used in non-organic production systems for the same purpose. Emulsified fish oil (FO) is frequently combined with LS to provide greater thinning efficacy (J. McFerson, personal communication). At this time the precise mode of action of LS as a bloom thinning agent is not known. Sulfur sprays may reduce germination (MacDaniels and Furr, 1930) and tube growth (He and Wetzstein, 1994) of pollen grains. The apple flower typically consists of five carpels, each containing two ovules so that there is the potential to develop ten seeds per fruit (Westwood, 1978). Parthenocarpy is seldom observed in most commercial cultivars, indicating that at least some embryo development is necessary for fruit retention. However, for preharvest drop

Received for publication 18 Oct. 2005. Accepted for publication 21 Dec. 2005. This research was supported by the New Zealand Foundation for Research Science and Technology Contract CO6X0005.

${ }^{1}$ Former research scientist and author to whom reprint requests should be addressed. Current address: Department of Horticultural Science, North Carolina State University, Mountain Horticultural Crops Research and Extension Centre, Fletcher, NC 28732-9244; e-mail steve_mcartney@ncsu.edu. at least, there does not appear to be any clear relationship between seed number in seeded fruit and their retention (Ward et al., 2001). Sinceflowers of 'Summerland McIntosh'exhibit perfect syncarpy, i.e., pollination levels among the five stigmas need not be uniform to obtain full seed development (Sheffield et al., 2005) then the potential seed number per fruit will be related more closely to the number of pollen tubes per flower than per style, and only the absence of pollen tubes from all styles in a flower will result in complete ovule abortion.

Sulfur may also suppress photosynthesis (Pn) in apple leaves (Hoffman, 1935; Hyre, 1939), and it has been proposed that postbloom LS applications thin apple fruit by inhibiting Pn and decreasing assimilate supply to developing fruit (Noordijk and Schupp, 2003). Palmer et al. (2003) have recently shown that using LS or sulfur as a fungicide over the whole season can reduce Pn of 'Braeburn' by almost 50\% in mid-summer. The current study was undertaken to quantify the effect of LS applications during bloom on pollen tube growth, spur leaf $\mathrm{Pn}$, and

\section{Materials and Methods}

Experiment 1: Number of LS applications, Nelson. Four-year-old 'Braeburn'/M.9 apple fruit set of apple. trees were selected and blocked into five replications of five trees in 2000. Liquid LS (3\%) was applied either $0,1,2,3$, or 4 times at 3 -d intervals during the bloom period, with the first application made when $30 \%$ of spurs were at full bloom (27 Sept. 2000). All treated trees received LS on the first date. Three, two, or one tree within each block received additional LS sprays 3,6 , or $9 \mathrm{~d}$ later respectively. Treatments were applied to fully guarded single-tree plots with a Solo backpack sprayer to the point of leaf wetness. Ten flowers at the late-balloon stage were tagged on each of the control trees and on each of the trees to receive a single LS application. The 50 flowers on each of these two treatments were tagged early on the day of the first LS application. LS applications were not made until mid afternoon. Tagged flowers were removed $5 \mathrm{~d}$ later (2 Oct.) to allow for sufficient pollen tube growth and stored in a 5\% sodium sulfite solution until later assessment of pollen tube growth.

The number of pollen tubes present at the mid point of each style was counted using the method of Embree and Foster (1999). Briefly, samples were autoclaved at $120^{\circ} \mathrm{C}$ for $20 \mathrm{~min}$ before squashing under a glass cover slip with water soluble $0.01 \%$ Aniline Blue stain in 0.067 м K $\mathrm{HPO}_{4}$. Stained samples were examined under a fluorescent light using a Nikon HB-10101 AF super high-pressure mercury lamp and a Nikon Optiphot photomicroscope (Nikon, Tokyo, Japan). Pollen tube number was expressed on a per flower basis rather than per individual style.

Leaf gas exchange was measured on two primary spur leaves per tree using an ADC LCA-3 portable leaf gas-exchange system (ADC, Hoddesdon, U.K.) under saturating light conditions $\left(>1,000 \mu \mathrm{mol} \cdot \mathrm{m}^{-2} \cdot \mathrm{s}^{-1}\right)$ at 3- to $4-\mathrm{d}$ intervals beginning one day after the first LS application. As the spur leaves of 'Braeburn' are small, the leaf cup described by Palmer (1986) was used rather than the broad leaf chamber of the LCA-3.

Treatment effects on initial fruit set (fruit per 100 flower clusters) were determined from flower cluster counts at bloom and fruit counts taken at the completion of fruit drop 38 $\mathrm{d}$ after bloom on two sample limbs on each tree. Sample limbs were chosen that were 8 to $10 \mathrm{~cm}$ in circumference and bore 40 to 60 clusters in total.

Experiment 2: $L S \pm F O$, Nelson. Five-yearold 'Braeburn'/M.9 apple trees were selected from within the same orchard as the previous study and blocked into six replications of four trees in 2001. Repeat applications of LS (2\%), either alone or in combination with FO (2\%) (Sealord Group, Nelson, New Zealand), were made three times during bloom in 2001 (27 Sept., 1 Oct., and 5 Oct.). Spray treatments containing FO were vigorously shaken during application to ensure the FO stayed in suspension. The treatments were applied with a Swissmex knapsack sprayer to fully guarded single-tree plots. Five flowers at the late balloon stage of development were tagged on each tree on the first day of LS application. Tagged flowers were harvested $5 \mathrm{~d}$ later (2 Oct.) to allow for sufficient pollen tube growth and stored in a $\%$ sodium sulfite solution 
Table 1. Effects of lime sulfur (3\%) application on the percent of flowers with limiting pollen tube number ( $<10$ or 0 pollen tubes per flower). Flowers at the full bloom stage of development on the day of treatment were sampled $5 \mathrm{~d}$ later. Percent data were analyzed after arcsine-square root transformation. Back-transformed weighted means are presented.

\begin{tabular}{lcc}
\hline & \multicolumn{2}{c}{$\begin{array}{c}\text { Flowers with limiting } \\
\text { pollen tube no. }(\%)\end{array}$} \\
\cline { 2 - 3 } Treatment & $<10$ tubes/flower & 0 tubes/flower \\
\hline Control & 8.6 & 2.0 \\
Lime sulfur & 64.3 & 27.1 \\
Significance $(P>$ F $)$ & 0.003 & 0.006 \\
\hline
\end{tabular}

until later assessment of pollen tube growth as in the previous study. Treatment effects on fruit set (fruit per 100 flower clusters) were determined from flower counts at bloom and fruit counts on two dates after bloom (initial fruit set counts taken on 5 Nov., $39 \mathrm{~d}$ after bloom; final fruit set counts taken on 7 Dec., $71 \mathrm{~d}$ after bloom) on two sample limbs on each tree. Treatment effects on leaf gas exchange of primary spur leaves were measured during the period from 1 to $57 \mathrm{~d}$ after the initial LS application using the same equipment as that described in the previous experiment.

Experiment 3: LS concentration and pollen tube number, Hawkes Bay. Four uniform mature 'Royal Gala'/M26 apple trees were selected in an orchard in 2001. Forty individual spurs were selected on each tree and the flowers removed by hand to leave a single flower on each spur at the full bloom stage of development. Ten individual flowers on each tree were sprayed with a hand sprayer with LS at a concentration of $0.5 \%, 1 \%$, or $4 \%$ and an additional ten flowers were left unsprayed on each tree. Flowers were sampled $8 \mathrm{~d}$ after LS treatments for assessment of pollen tube growth as in the previous experiments.

Statistical analysis. The general linear models (GLM) procedure of the Statistical Analyis System (SAS, Cary, N.C.) was used to test for treatment effects on pollen tube number and fruit set. The percent of flowers with a limiting pollen tube number ( $<10$ or 0 tubes per flower) were calculated from pollen tube data and analyzed after arcsine-square root transformation to normalize variances. Regression procedures were used to model the effect of number of LS applications on fruit set and the effect of LS concentration on the percent of flowers with a limiting number of pollen tubes. Experiment 2 was analyzed as a $2 \times 2$ factorial design experiment; main effect means are presented where the interaction term in the model was not statistically significant. Pn data were analyzed using the GenStat (VSN International Ltd. Herts, UK) statistical software system. Treatment effects on Pn were tested both between groups and within subjects (Time).

\section{Results and Discussion}

Pollen tube growth. Application of LS during bloom increased the percentage of flowers with fewer than ten pollen tubes per flower in all experiments. In Expt. 1, only 9\% of flowers that opened on the day of treatment had $<10$ pollen tubes per flower, compared to $64 \%$ of flowers at the same stage on trees sprayed with 3\% LS. In the same study, LS increased the percent of flowers with no pollen tubes to $27 \%$, compared to only $2 \%$ in the control (Table 1). There was no effect of $\mathrm{FO}$ on the number of pollen tubes per flower in Expt. 2, but LS increased the proportion of flowers with less than ten pollen tubes to $82 \%$ compared to only $5 \%$ in the control. Additionally, pollen tubes were completely absent from $48 \%$ of the flowers on trees sprayed with LS compared to $4 \%$ on control trees (Table 2). Data collected in Expt. 3 indicated that the number of pollen tubes per flower was inversely related to the concentration of LS; $4 \%$ LS resulted in $63 \%$ of flowers with $<10$ pollen tubes and $38 \%$ of flowers with no pollen tubes, compared to $3 \%$ and $0.4 \%$ in the control, respectively (Fig. 1).

Flowers were not hand-pollinated in these experiments, so a reduced number of pollen tubes per flower following LS treatments could be attributed to any or a combination of factors including a reduced frequency of visits by pollinating insects, desiccation of the pollen grain on the stigmatic surface, or aberrant germination and growth of the pollen tube itself. Sheffield et al.(2005)reported that 'Summerland McIntosh' apple flowers exhibited perfect syncarpy; it was not necessary for all stigmata to be pollinated in order to obtain uniform pollen tube distribution and full fertilization of the ovules within an apple flower. Assuming all pollen tubes that were observed at the midpoint of the style continue growing to reach the micropyle and successfully fertilize the ovule then pollen tube number per flower should also reflect the potential seed number per fruit. Whereas unpollinated flowers will not usually set fruit (Sheffield et al., 2005), fruit with low seed counts $(<4)$ can develop normally and will frequently persist until harvest. Therefore, while the proportion of flowers with $<10$ pollen tubes will reflect a reduction in potential seed number per fruit, it may not necessarily reflect a reduced fruit set potential. However, the probability that flowers with no pollen tubes, and fruit with no seeds, will set is very low.

Application of LS resulted in $27 \%$ to $48 \%$ of newly opened flowers having no pollen tubes present in the style compared to only $4 \%$ or less of flowers on control trees. Therefore, at least one third of the flowers that are at full bloom on each day that LS is applied are unlikely to set a fruit due to complete inhibition of ovule fertilization. MacDaniels and Furr(1930) found that set was also reduced when sulfur (dusting) was applied $24 \mathrm{~h}$ after hand pollination, although the reduction in fruit set was not as great as when sulfur was applied on the day of pollination. It is probable therefore that flowers that have been open for only one day may also exhibit a reduced fruit set potential via a similar mechanism. Asynchronous development of apple flowers typically occurs at several levels within a tree; the king flower will develop before lateral flowers within the same spur, flowers on 1-year wood will typically develop later than flowers on older wood, and flowering time will vary depending on location of the cluster within the tree canopy. If the mode of action of LS thinning sprays is solely due to the complete inhibition of fertilization of some flowers, then the efficacy of this treatment will be directly related to the proportion of the total population of flowers that are open on the day of treatment, and more frequent applications may be required when the bloom period is protracted.

Leaf Pn. A single application of LS (3\%) reduced the rate of light saturated leaf $\mathrm{Pn}$ to $84 \%$ and $74 \%$ of the control value 8 and $12 \mathrm{~d}$ after treatment respectively in Expt. 1 (Table 3). The rate of Pn had recovered when measured $19 \mathrm{~d}$ after treatment. A second application of LS $3 \mathrm{~d}$ after the initial application further reduced Pn to $57 \%$ of the control value. The effects of successive applications of LS on Pn were additive; four applications reducing Pn to only $53 \%$ of the control value. The suppression of Pn by LS in Expt. 1 was no longer evident when measured $30 \mathrm{~d}$ after the initial application, $21 \mathrm{~d}$ after the final LS application. In contrast, treatment effects on Pn were still evident $57 \mathrm{~d}$ after the initial LS application in Expt. 2, $51 \mathrm{~d}$ after the final application (Table 4). FO reduced Pn by $10 \%$ whereas LS reduced Pn by $20 \%$. The significant interaction of time and LS indicate that leaf Pn changed differently over time for each level of LS. In all cases stomatal conductance was significantly reduced with decreased leaf Pn (data not shown).

The data presented in Table 3 indicate that the inhibitory effect of LS on Pn of primary

Table 2. Main effects of repeated applications of lime sulfur (2\%) or FO (2\%) during bloom in 2001 on the percent of flowers with limiting pollen tube numbers $(<10$ or 0 pollen tubes per flower), initial and final fruit set. Flowers were collected for assessment of pollen tube number $5 \mathrm{~d}$ after the first of three applications, initial and final fruit set were recorded 39 and $71 \mathrm{~d}$ after bloom respectively. Percent data were analyzed after arcsine-square root transformation. Back-transformed weighted means are presented.

\begin{tabular}{|c|c|c|c|c|}
\hline \multirow{2}{*}{$\begin{array}{l}\text { Main } \\
\text { effects }\end{array}$} & \multicolumn{2}{|c|}{$\begin{array}{c}\text { Flowers with limited } \\
\text { pollen tube no. }(\%)\end{array}$} & \multicolumn{2}{|c|}{$\begin{array}{c}\text { Fruit set } \\
\text { (fruit/100 clusters) }\end{array}$} \\
\hline & $<10$ tubes/flower & 0 tubes/flower & Initial set & Final set \\
\hline \multicolumn{5}{|l|}{ Lime sulfur } \\
\hline No lime sulfur applied & 5 & 4 & 66.4 & 58.9 \\
\hline Lime sulfur & 82 & 48 & 40.5 & 38.8 \\
\hline \multicolumn{5}{|l|}{ Fish oil } \\
\hline No fish oil applied & 33 & 16 & 59.8 & 54.2 \\
\hline Fish oil & 41 & 26 & 47.1 & 43.4 \\
\hline \multicolumn{5}{|l|}{ Significance $(P>\mathrm{F})$} \\
\hline Lime sulfur & $<0.0001$ & $<0.001$ & $<0.0001$ & $<0.0001$ \\
\hline Fish oil & 0.52 & 0.29 & 0.006 & 0.015 \\
\hline Interaction & 0.80 & 0.29 & 0.36 & 0.84 \\
\hline
\end{tabular}




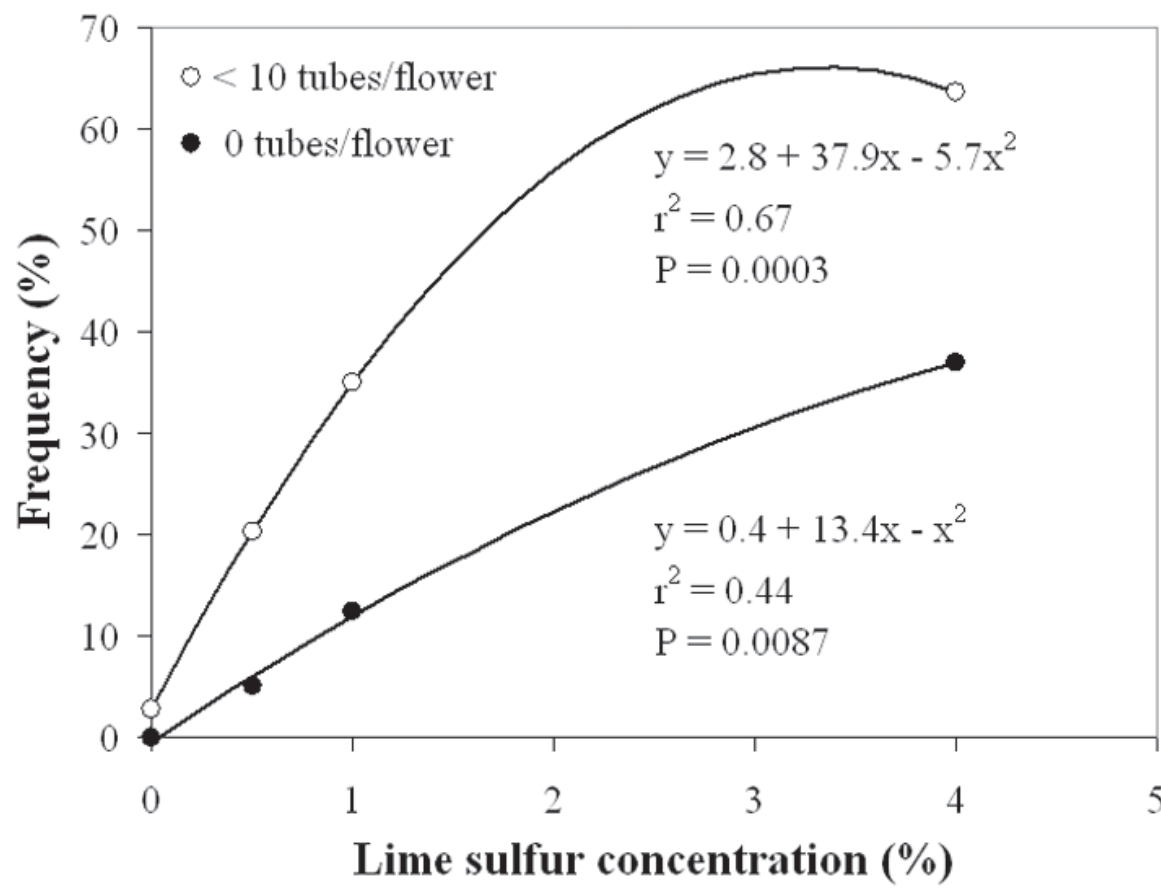

Fig. 1. Effect of lime sulfur concentration on the percent of flowers with limiting total pollen tube numbers per flower $(<10$ or 0 pollen tubes per flower). Flowers were sampled $8 \mathrm{~d}$ after treatment.

Table 3. Effects of number of lime sulfur (3\%) applications beginning at 30\% spur full bloom (2000) on light-saturated $\mathrm{Pn}\left(\mu \mathrm{mol} \cdot \mathrm{m}^{-2} \cdot \mathrm{s}^{-1}\right)$ of primary spur leaves on 'Braeburn'/M.9 apple trees during the $30-\mathrm{d}$ period following the initial application. All treated trees received lime sulfur on day zero. Trees receiving 2,3 , or 4 LS applications were sprayed 3, 3 and 6 , and 3,6, and 9 d later respectively.

\begin{tabular}{|c|c|c|c|c|c|c|c|}
\hline \multirow{2}{*}{$\begin{array}{l}\text { LS sprays } \\
\text { (no.) }\end{array}$} & \multicolumn{6}{|c|}{ Time of Pn measurement (days after initial application) } & \multirow{2}{*}{$\begin{array}{c}\text { Mean LS } \\
\text { sprays (no.) }\end{array}$} \\
\hline & 1 & 5 & 8 & 12 & 19 & 30 & \\
\hline 0 & 11.9 & 13.4 & 16.0 & 15.7 & 15.0 & 16.2 & 14.7 \\
\hline 1 & 10.8 & 11.0 & 13.5 & 11.6 & 14.0 & 15.8 & 12.8 \\
\hline 2 & 12.4 & 12.0 & 13.4 & 9.0 & 13.3 & 14.8 & 12.5 \\
\hline 3 & 12.6 & 10.0 & 10.2 & 9.9 & 11.1 & 14.1 & 11.3 \\
\hline 4 & 12.7 & 9.3 & 10.6 & 8.8 & 7.9 & 14.3 & 10.6 \\
\hline Mean (time) & 12.1 & 11.1 & 12.7 & 11.0 & 12.3 & 15.0 & \\
\hline Source & $\mathrm{df}$ & $P$ & $\mathrm{LSD}_{0.05}$ & & & & \\
\hline LS sprays (no.) & 4 & $<0.001$ & 1.3 & & & & \\
\hline Linear & 1 & $<0.001$ & & & & & \\
\hline Quadratic & 1 & 0.380 & & & & & \\
\hline Time & 5 & $<0.001$ & 1.2 & & & & \\
\hline No. LS sprays $\times$ time & 20 & $<0.001$ & $2.7^{\mathrm{z}}$ & & & & \\
\hline Linear $\times$ time & 5 & $<0.001$ & & & & & \\
\hline Quadratic $\times$ time & 5 & 0.065 & & & & & \\
\hline
\end{tabular}

${ }^{2} \mathrm{LSD}_{0.05}=2.6$ when comparing means within the same level of number of LS sprays.

spur leaves reached a maximum around 12 to $14 \mathrm{~d}$ after application. However, the pattern of recovery of Pn was different in each experiment; Pn rates recovered within $19 \mathrm{~d}$ of the initial treatment in Expt. 1 whereas the inhibitory effects of LS were still evident $51 \mathrm{~d}$ after the initial application in Expt. 2. This may reflect the greater care taken in Expt. 2 to select only those spur leaves receiving LS. There were no effects of any of the LS treatment on Pn of fully expanded basal extension shoot leaves on 16 Oct. 2000 in Expt. 1 (data not shown), indicating that leaves which would have been barely visible when LS sprays were applied were not affected. This emphasizes that the reduction in $\mathrm{Pn}$ at the whole canopy level may be more transitory than the reduction measured at the individual spur leaf level. The rapid development of normally functioning extension shoot leaf area following LS applications during identifying the period from 2 to 4 weeks after bloom as a critical time when the probability is highest for fruit production being limited by carbohydrate supply. The extent and duration of inhibition of Pn that were measured in the current experiments following LS applications at bloom are consistent with a thinning effect via reduction of carbon supply to developing fruit for the cultivar 'Braeburn' at least. However, if the Pn response to LS is less sensitive in other cultivars then the thinning response would be less sensitive also. We have measured milder suppression and more rapid recovery of $\mathrm{Pn}$ in other apple cultivars in response to LS applications (unpubl. data). If the thinning response is due entirely to a reduction in carbohydrate supply to developing fruit then a reduced thinning efficacy would be expected for cultivars other than 'Braeburn'.

Fruitset. There was a significant linear effect of the number of LS applications during bloom on fruit set; each successive application of LS reduced fruit set by an additional $10.2 \%$ of the control value (Fig. 2). In Expt. 2 the interaction term between the two main factors (LS and FO) was not significant so only main affect means are presented (Table 2). FO reduced both initial and final fruit set by about $20 \%$. LS had a greater effect on initial and final fruit set than FO, reducing it by $39 \%$ and $34 \%$, respectively.

A single application of LS resulted in $27 \%$ of the flowers that were at full bloom on the day of treatment having no pollen tubes present in their styles, and therefore unable to develop any embryos or set a fruit (Expt. 1). Subsequent applications of LS would presumably have a similar effect on flowers that were at full bloom on the day of application, and so have a cumulative effect on fruit set. It is not known at this time if subsequent LS applications also have a suppressive effect on embryo development within flowers in which fertilization has been limited by earlier LS sprays. If LS does limit the potential for embryo development in flowers that have been open for only 1 or $2 \mathrm{~d}$, then this could explain the levels of fruit abscission that are commonly observed with thinning sprays of LS. However, repeat applications of LS during bloom also resulted in a cumulative suppression of Pn, the extent and duration of which could arguably have resulted in fruit abscission via a transient reduction in the supply of carbohydrates to the growing fruit according to current hypotheses (Beruter and Droz, 1991; Lakso et al., 1999; Stopar et al., 2000; Untiedt and Blanke, 2001).

The interaction term between LS and FO was not statistically significant for fruit set, pollen tube growth, or photosynthesis data in Expt. 2. There was a significant main effect of both LS and FO on fruit set and Pn, yet only LS had a significant effect on the percent of flowers with limiting numbers of pollen tubes. FO reduced Pn by about $10 \%$ percent, with this effect still evident on the final day of measurement, 51 $\mathrm{d}$ after the final application. Even though this represents only a mild suppression of Pn, the cumulative effect on whole tree carbon balance throughout this period must have reduced carbon availability to developing fruit to the extent that fruit abscission was triggered. Commercial 
Table 4. Effects of three applications of $2 \%$ lime sulfur (LS) and $2 \%$ fish oil (FO) during bloom in 2001 , on light-saturated Pn $\left(\mu \mathrm{mol} \cdot \mathrm{m}^{-2} \cdot \mathrm{s}^{-1}\right)$ of primary spur leaves on 'Braeburn'/M.9 apple trees during the 57-d period following the first application. LS and FO were applied alone or in combination. The second and third sprays were applied 3 and $6 \mathrm{~d}$ after the initial application respectively.

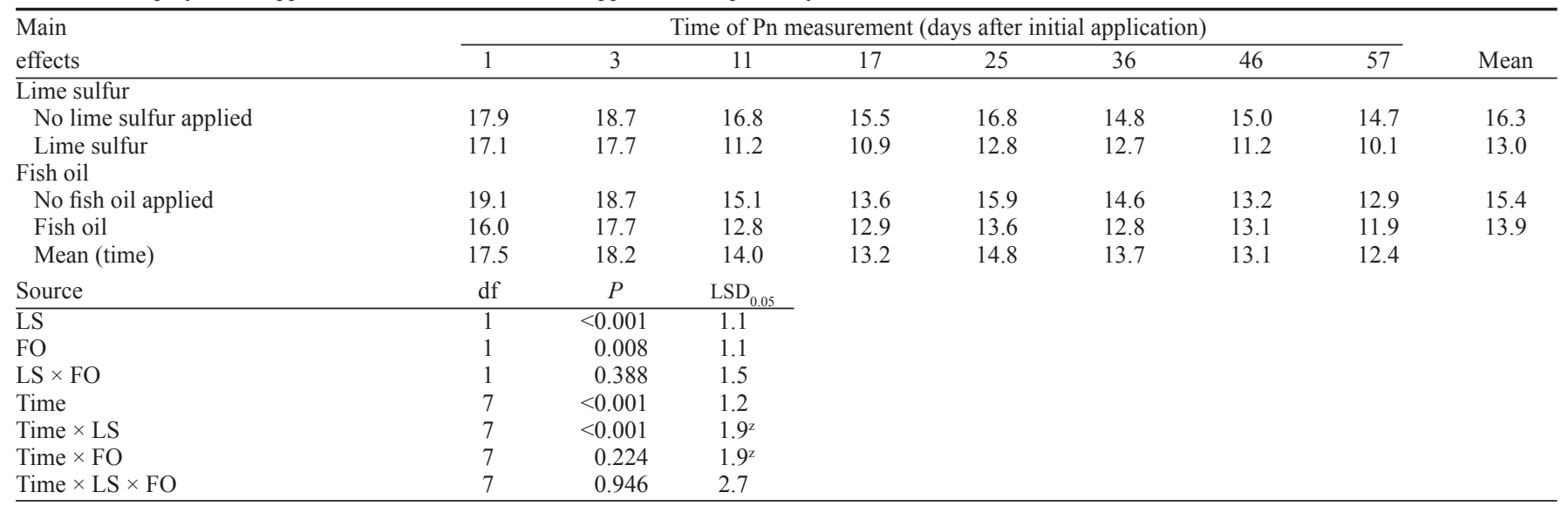

${ }^{{ }^{2} \mathrm{LS}_{0.05}}=1.7$ when comparing means within the same level of LS or FO.

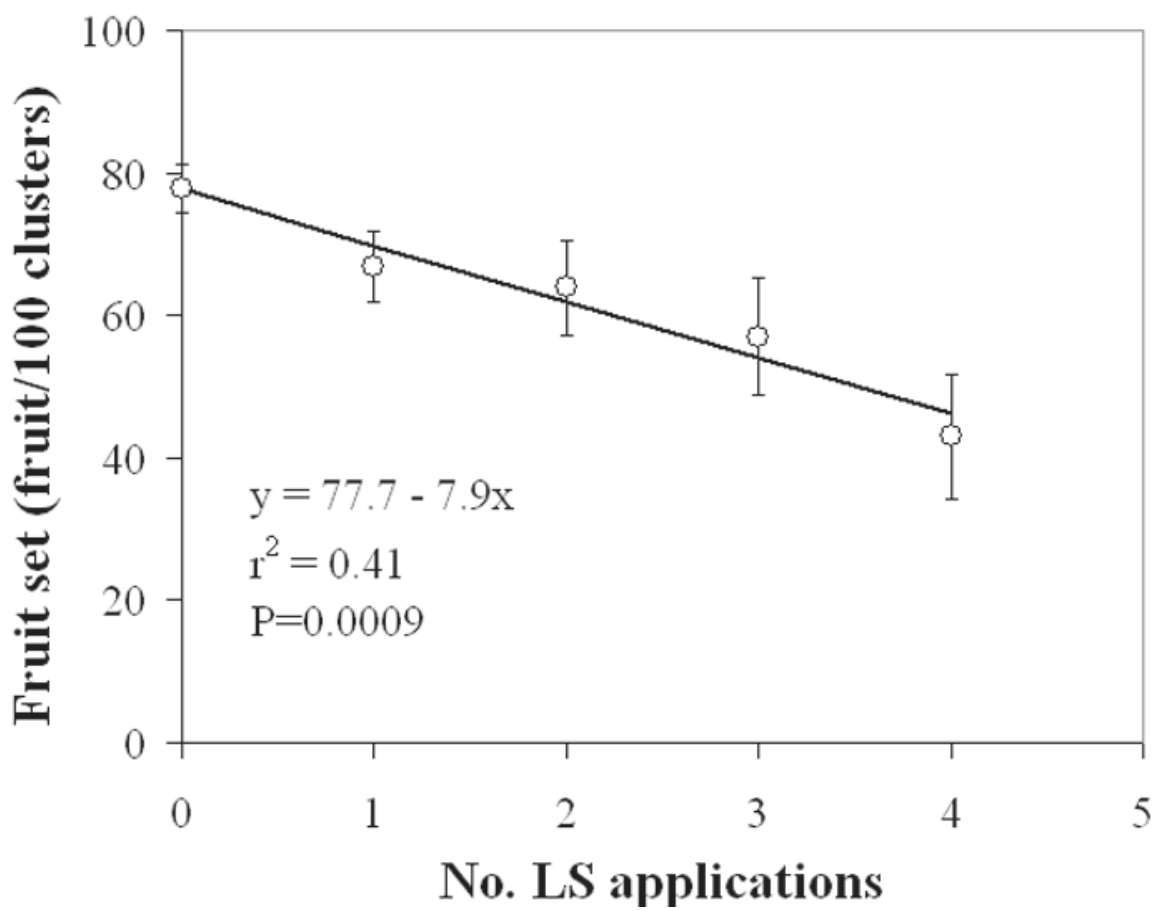

Fig. 2. Effects of number of applications of LS (3\%) during bloom on fruit set of 'Braeburn' apples. LS applications were made every $3 \mathrm{~d}$ beginning at 30\% spur full bloom (27 Oct. 2000). Data points are the mean of five replications with bars representing \pm standard error of the mean.

formulations of FO contain an emulsifying agent to maintain the oil in a stable suspension. Emulsified FO may have different effects on pollination, Pn and fruit set compared to the FO treatments used in Expt. 2

From these data it appears that fruit abscission following applications of LS to apples over the bloom period is the result of the combined effects of an increase in the number of completely unfertilized flowers and a reduction in carbohydrate supply to fertilized flowers due to a suppression in the rate of Pn in primary spur leaves. While the suppression of spur leaf Pn following LS applications may be permanent, the effect of LS on whole tree carbon balance may be more transitory due to an increasing contribution of newly assimilated carbon from rapidly expanding extension shoot leaves during this period. If the abscission response following bloom thinning sprays of LS is largely due to a transient suppression of whole-tree carbon acquisition, then thinning results would be highly variable, and dependent on a myriad of factors including the photosynthetic response of the individual cultivar, ambient light and temperature conditions, crop load, availability of carbohydrate reserves and current assimilates. Yetpersonal observation and grower experience have demonstrated that repeat applications of LS + FO over the bloom period are a consistently effective chemical thinning strategy.

\section{Literature Cited}

Beruter, J. and P. Droz. 1991. Studies on locating the signal for fruit abscission in the apple tree. Scientia Hort. 46:201-214.

Byers, R.E., J.A. Barden, R.F. Polomski, R.W. Young and D.H. Carbaugh. 1990. Apple fruit abscission by photosynthetic inhibition. J. Amer. Soc. Hort. Sci.
115:14-19.

Byers, R.E., D.H. Carbaugh, C.N. Presley and T.K. Wolf. 1991. The influence of low light on apple fruit abscission. J. Hort. Sci. 66:1-7.

Embree, C.G. and A. Foster Jr. 1999. Effects of coatings and pollenicides on pollen tube growth through the stigma and style of 'McIntosh' apple blossoms. J. Tree Fruit Prod. 2:19-32.

He, Y. and H.Y. Wetzstein. 1994. Pollen degeneration and related leafdevelopment from fungicidal sprays applied during microspore development and shoot expansion. J. Hort. Sci. 69:975-983.

Hoffman, M.B. 1935. The effect of lime-sulfur spray on the respiration rate of apple leaves. Proc. Amer. Soc. Hort. Sci. 33:173-176.

Hyre, R.A. 1939. The effect of sulfur sprays on the photosynthesis and transpiration of apple leaves. N. Y. Agr Expt. Sta. Mem. 222.

Lakso, A.N., J.N. Wunsche, J.E. Palmer and L. CorelliGrappadelli. 1999. Measurement and modeling of carbon balance of the apple tree. HortScience 34:1040-1047.

MacDaniels, L.H. and J.R. Furr. 1930. The effect of dusting-sulfur upon the germination of the pollen and the set of fruit of the apple. Bul. Cornell Univ. Agr. Expt. Sta. 499.

McArtney, S., M. White, I. Latter and J. Campbell. 2004. Individual and combined effects of shading and thinning chemicals on abscission and dry-matter accumulation of 'Royal Gala' apple fruit. J. Hort. Sci. Biotechnol. 79:441-448.

Noordijk, H. and J. Schupp. 2003. Organic post bloom apple thinning with FO and lime sulfur. Hortscience 38:690 (abstr.)

Palmer, J.W. 1986. Seasonal variation of light saturated photosynthetic rate of Golden Delicious apple leaves as influenced by leaf type and crop load, p. 30-33. In: A.N. Lakso and F.Lenz (eds.). The regulation of photosynthesis in fruit trees. Symp. Proc. N.Y. State Agr. Expt. Sta., Geneva.

Palmer, J.W., S.B. Davies, P. Shaw, and J.N. Wünsche. 2003 Growth and fruit quality of 'Braeburn' apple trees as influenced by fungicide programmes suitable for organic production. N.Z. J. Crop Hort. Sci. 31:169-177.

Sheffield, C.S., R.F. Smith, and P.G. Kevan. 2005. Perfect syncarpy in apple (Malus $\times$ domestica 'Summerland McIntosh') and its implications for pollination, seed distribution and fruit production(Rosaceae: Maloideae). Ann. Bot. 95:583-591.

Stopar, M., A. Gregor, and F. Bati. 2000. Apple fruit abscission is influenced by assimilate supply. Acta Hort. 527:169-178.

Untiedt, R. and M. Blanke. 2001. Effects of fruit thinning agents on apple tree canopy photosynthesis and dark respiration. Plant Growth Reg. 35:1-9.

Ward, D.L., R.P.Marini, and R.E. Byers. 2001. Relationships among day of year of drop, seed number, and weight of mature apple fruit. HortScience 36:5-48.

Westwood, M.N. 1978. Temperate zone pomology. W.H. Freeman and Co., San Francisco. 